\title{
Low Actuating Voltage Spring-Free RF MEMS SPDT Switch
}

\author{
Deepak Bansal, ${ }^{1,2}$ Anuroop Bajpai, ${ }^{1}$ Prem Kumar, ${ }^{1}$ Maninder Kaur, ${ }^{1}$ and Kamljit Rangra ${ }^{1,2}$ \\ ${ }^{1}$ Central Electronics Engineering Research Institute (CEERI), Council of Scientific and Industrial Research (CSIR), Pilani, \\ Rajasthan 333031, India \\ ${ }^{2}$ Academy of Scientific and Innovative Research (AcSIR), New Delhi, India
}

Correspondence should be addressed to Deepak Bansal; dbansal.pu@gmail.com

Received 9 July 2016; Accepted 28 August 2016

Academic Editor: Jit S. Mandeep

Copyright (C) 2016 Deepak Bansal et al. This is an open access article distributed under the Creative Commons Attribution License, which permits unrestricted use, distribution, and reproduction in any medium, provided the original work is properly cited.

RF MEMS devices are known to be superior to their solid state counterparts in terms of power consumption and electromagnetic response. Major limitations of MEMS devices are their low switching speed, high actuation voltage, larger size, and reliability. In the present paper, a see-saw single pole double throw (SPDT) RF MEMS switch based on anchor-free mechanism is proposed which eliminates the above-mentioned disadvantages. The proposed switch has a switching time of 394 nsec with actuation voltage of $5 \mathrm{~V}$. Size of the SPDT switch is reduced by utilizing a single series capacitive switch compared to conventional switches with capacitive and series combinations. Reliability of the switch is improved by adding floating metal and reducing stiction between the actuating bridge and transmission line. Insertion loss and isolation are better than $-0.6 \mathrm{~dB}$ and $-20 \mathrm{~dB}$, respectively, for $1 \mathrm{GHz}$ to $20 \mathrm{GHz}$ applications.

\section{Introduction}

Development of miniature wireless communications devices like mobile and satellite requires components with minimum power consumption with better performance. The RF MEMS devices are known to be better compared to solid state devices due to their low power consumption, high isolation, and low insertion loss. RF MEMS SPDT switches constitute the basic building block of the RF MEMS systems like SP4T [1], phase shifter [2], switch matrix [3], other communication systems [4], and so forth. The RF MEMS devices are also known to have few drawbacks too, for example, low switching speed $(20-200 \mu \mathrm{sec})$, high pull-in voltage $(15-80 \mathrm{~V})$, larger size, and reliability $[5,6]$. These issues at present limit the utilization of the MEMS devices on a larger scale. These mechanical parameters are function of spring constant and pull-in voltage. The conventional anchoring of a rectangular membrane is through two Euler beams where one end along the length is fixed to the membrane and the other to anchor post on either side of the membrane. When a voltage is applied between the movable and the fixed membrane of the switch as shown in Figure 1, the bridge moves down onto the fixed ground under the electrostatic force. At the pull-in voltage, the switch is in the down state
[7] which is calculated using $1 \mathrm{D}$ lumped model as shown in Figure 1.

From lumped model neglecting higher order effects as mentioned in [7], actuation voltage of the switch is given by

$$
V_{p}=\sqrt{\frac{8 k g^{3}}{27 A \varepsilon_{o}}},
$$

where $k$ is spring constant and $g$ and $A$ are gap and area of overlap between the actuation electrode and the bridge.

From (1), actuation voltage can be lowered by (i) increasing the overlap area $(A)$, (ii) decreasing the gap $(g)$, or (iii) decreasing spring constant $(k)$.

Each method has its own demerits; for example, (i) large overlap area $(A)$ enhances stiction forces as stiction is directly proportional to contact area $[6,8]$. Therefore, actuating electrode area is optimized based on stiction and restoring force [6].

Smaller gap $(g)$ promotes stiction by reducing beam restoring force, which is proportional to the beam displacement. Smaller gap also adversely affects switch isolation through enhanced capacitive leakage. The bridge gap is also limited by the available fabrication technology and has been set in the range of $1-4 \mu \mathrm{m}$. 


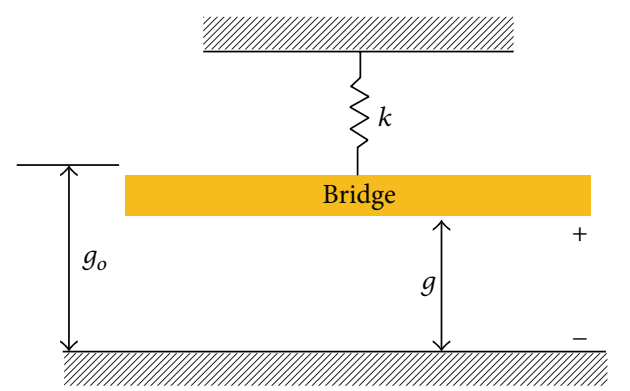

FIGURE 1: 1D lumped model for actuation voltage calculation.

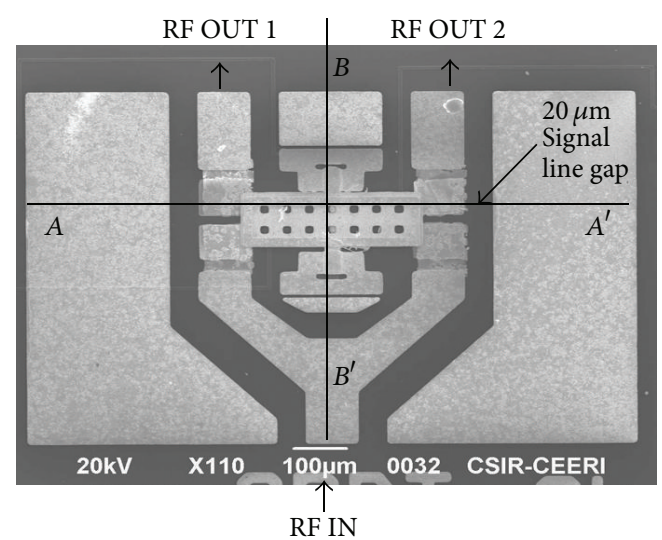

FIGURE 2: SEM image of a spring-free see-saw RF MEMS capacitive switch.

Decreasing $k$ makes the beam complaint and prone to stiction. Further, switching time and pull-in voltage are inversely corelated to spring constant; devices with low pullin voltage are slow to change state. In the present paper, a novel RF MEMS series capacitive SPDT switch based on anchor-free torsional configuration is proposed as shown in Figure 2. In the new configuration, as shown in Figures 3 (a) and 3(b), anchoring is replaced by spring-free see-saw mechanism. The configuration has the advantages of low actuation voltage with high switching speed as discussed in Section 5 .

\section{SPDT Switch Description}

The anchor-free see-saw SPDT designed for S-Ku band is similar to ohmic SPDT except for the contact points that are capacitive in this case. The capacitive contacts have an advantage of high operating frequency as described in [9]. Selection of the switch parameters is made based on available fabrication technology and electromechanical response of the switch. Input and output ports are made of $50 \mathrm{ohm}$ Y-shaped CPW configuration (55-90-55 $\mu \mathrm{m}$ ) for external connections. The bridge gap, dielectric material, and bridge thickness are decided by fabrication capabilities. The bridge gap lies in the range of $1-4 \mu \mathrm{m}$ based on final releasing process, fixed at $2 \mu \mathrm{m}$ in the present design. Silicon dioxide is selected as a dielectric material due to its well-known behavior. Floating metal area is selected based on operating frequency and bandwidth as
TABLE 1: Design parameters used in the proposed switch design.

\begin{tabular}{llcc}
\hline $\begin{array}{l}\text { S. } \\
\text { number }\end{array}$ & Design parameter & Value & Unit \\
\hline 1 & CPW (G-S-G) & $55-90-55$ & $\mu \mathrm{m}$ \\
2 & Anchor dimension & $40 * 50$ & $\mu \mathrm{m}^{2}$ \\
3 & Oxide thickness & 0.1 & $\mu \mathrm{m}$ \\
4 & Oxide dielectric constant & 3.9 & \\
5 & Floating metal thickness & 0.1 & $\mu \mathrm{m}$ \\
6 & Floating metal area & $2 * 65 * 90$ & $\mu \mathrm{m}^{2}$ \\
7 & Bridge thickness & 4 & $\mu \mathrm{m}$ \\
8 & Bridge length & 300 & $\mu \mathrm{m}$ \\
9 & Bridge width & 100 & $\mu \mathrm{m}$ \\
10 & Bridge height above float metal & 2 & $\mu \mathrm{m}$ \\
11 & Clamp thickness & 4 & $\mu \mathrm{m}$ \\
12 & Support thickness & 3 & $\mu \mathrm{m}$ \\
13 & Support dimensions & $10 * 100$ & $\mu \mathrm{m}^{2}$ \\
14 & Signal line gap & 20 & $\mu \mathrm{m}$ \\
15 & Actuating electrode area & $100 * 80$ & $\mu \mathrm{m}^{2}$ \\
16 & Chip size & $1080 * 680$ & $\mu \mathrm{m}^{2}$ \\
\hline
\end{tabular}

it decides the capacitive ratio explained in Section 3 [8]. The actuation pads and bridge dimensions are fixed to keep pullin voltage less than $5 \mathrm{~V}$. The bridge and clamps are made of thick $(4 \mu \mathrm{m})$ gold to avoid curling/buckling of the bridge. The signal line gap is fixed to $20 \mu \mathrm{m}$, lower gap leads to poor isolation, and higher gap needs larger width of the bridge to keep overlap capacitance fixed. All the parameters utilized in designing the SPDT switch are listed in Table 1. The SPDT switch utilizes single series capacitive switch which makes its size $\left(1.080 \times 0.680 \mathrm{~mm}^{2}\right) 85 \%$ compact compared to the literature, for example, $5.2 \times 3 \mathrm{~mm}^{2}$ [9], $3.8 \times 1.1 \mathrm{~mm}^{2}$ [10], and $3.5 \times 1.5 \mathrm{~mm}^{2}[11]$.

\section{Working of the Switch}

Working of the see-saw switch is similar to conventional switches. On actuation, the bridge lands on one side of the transmission line as shown in Figures 3(a) and 3(b) and connects the input port to the output port. The other side of the bridge is lifted upwards and no signal is passed.

In OFF state, the switch (bridge) is in an upward tilted position that results in OFF state capacitance $\left(C_{\text {off }}\right)$ of $0.885 \mathrm{fF}$ as shown in Figures 4(a) and 4(c):

$$
\begin{aligned}
C_{\text {off }} & =\varepsilon_{o} \\
& \cdot \frac{(\text { Bridge width }- \text { Signal line gap }) / 2 * \text { Bridge overlap }}{\text { Bridge height from floating metal }} \\
& =\varepsilon_{o} \frac{(100-20) / 2 * 5}{2}=0.885 \mathrm{fF} .
\end{aligned}
$$

The capacitance $(0.885 \mathrm{fF})$ between the input and output lines (reactance $1 / \omega C>10 \mathrm{k} \Omega$ for $\mathrm{S}$-Ku band) provides good isolation. RF coupling between the signal lines through the bridge is negligible and can be neglected. Working principle 


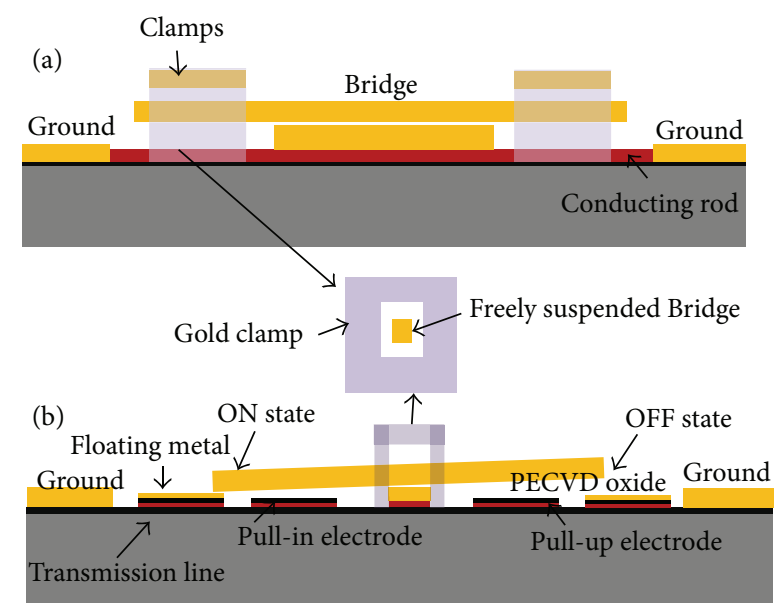

FIGURE 3: Cross-sectional view of working the SPDT switch (a) across $\mathrm{AA}^{\prime}$ and (b) across $\mathrm{BB}^{\prime}$.

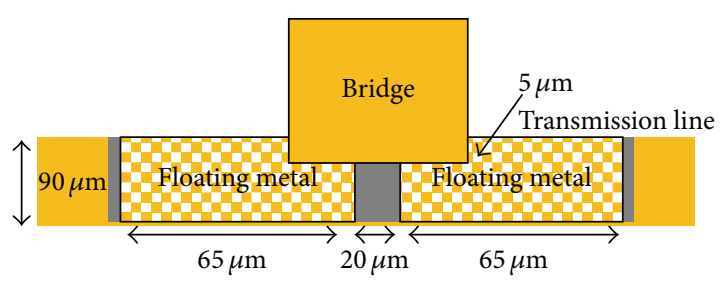

(a) Top view of the bridge and contact area

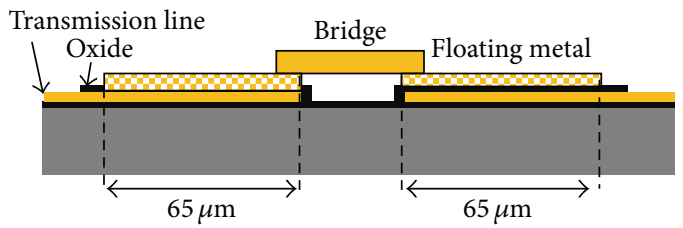

(b) Cross-sectional view of the bridge and contact area in $\mathrm{ON}$ state

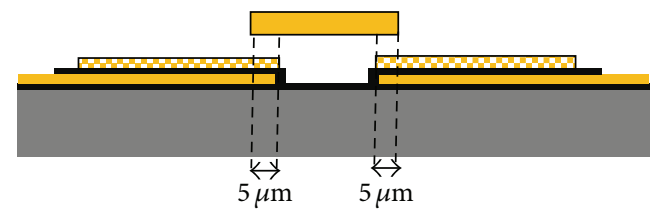

(c) Cross-sectional view of the bridge and contact area in OFF state

Figure 4: (a) Top view, (b) cross-sectional view in ON state, and (c) cross-sectional view in OFF state at the bridge and contact area.

is demonstrated in Figure 5. In ON state, the bridge tilts and contacts the metal layer (called float metal) on the t-line.

This results in an effective overlap capacitance of $2 \mathrm{pF}$ (area $65 \times 90 \mu \mathrm{m}^{2}$ ) between the bridge and t-line (Figures 3(a) and $3(\mathrm{~b})$ ) offering small reactance ( $<26 \Omega$, for S-Ku band) to the signal passing from input to output port via the bridge.

\section{Fabrication Process Flow}

The fabrication process flow for the SPDT switch is illustrated in Figures 6(a)-6(i). The process begins with growth of one-micron-thick thermal oxide on high resistive $\mathrm{Si}$ wafer. LPCVD deposited polysilicon which constitutes the actuation electrodes and DC bias lines is doped with phosphorus to achieve required sheet resistance followed by PECVD oxide for isolation. A $0.1 \mu \mathrm{m}$ thin Ti/TiN layer (float metal) is sputtered followed by $\mathrm{Cr} / \mathrm{Au}$ seed layer of thickness $20 \mathrm{~nm} / 80 \mathrm{~nm}$ and electroplated to get $3 \mu \mathrm{m}$ thickness supports as shown in Figure 6(e). A sacrificial layer (HIPR) is spin coated to make a mold for bridge structure followed by again $\mathrm{Cr} / \mathrm{Au}$ seed layer of thickness $30 \mathrm{~nm} / 50 \mathrm{~nm}$ with electroplating to get $4 \mu \mathrm{m}$ stiff bridge structures as shown in Figure 6(g). The process of sacrificial layer and gold plating is repeated to make $4 \mu \mathrm{m}$ thick clamps for the bridge as shown in Figure 6(i). The final structure is released with wet etching using critical point dryer (CPD) machine. The final fabricated SPDT switch is shown in Figure 2.

\section{Mechanical Characteristics}

The RF MEMS devices have a better electromagnetic response compared to the solid state devices but mechanical parameters like biasing voltage, speed, and reliability are inferior which limit their applications. The proposed spring-free system has addressed the above drawbacks as follows.

5.1. Actuation Voltage. The proposed switch design is free from the spring action, and acting restoring force is negligible. The only gravitational force has control over the actuation. Electrostatic force required to operate the switch must overcome the gravitational force as given below:

$$
F_{e}=\frac{1}{2} \frac{\varepsilon_{o} A V_{\mathrm{act}}^{2}}{g_{o}^{2}} \geq m g
$$

where $g$ is a gravitational constant.

From (3), required actuating voltage is

$$
V_{\text {act(min) }}=\sqrt{\frac{2 g m g_{o}^{2}}{\varepsilon_{o} A}}
$$

For the proposed switch parameters as listed in Table 1, actuation voltage turns out to be $1.7 \mathrm{~V}$. However, on measurements in open environment, actuation voltage turns out to be $5 \mathrm{~V}$ due to bridge damping and friction between hinges and clamps which is much less than actuation voltage reported in the literature [3-15]. Comparisons for size, pull-in voltage, switching time, and number of switches utilized in the present SPDT switch are described in Table 2.

5.2. Switching Speed. Resonance frequency and switching speed of the SPDT switch are extracted from 1D nonlinear model given by

$$
m \frac{d^{2} x}{d t^{2}}+b \frac{d x}{d t}+k x=F_{e}
$$




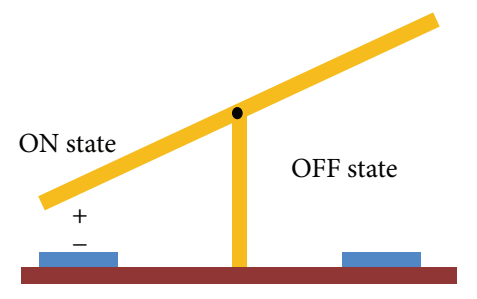

(a)

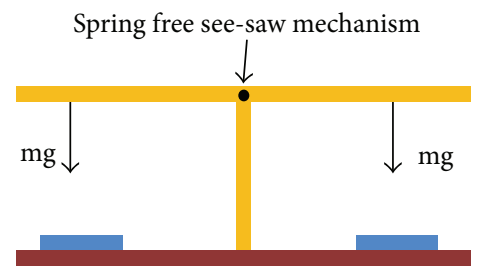

(b)

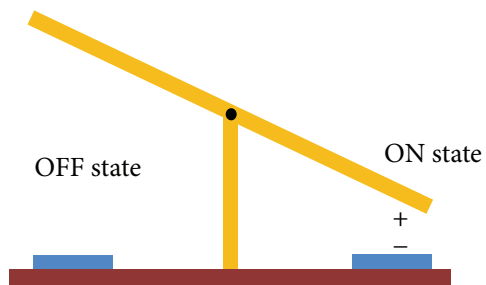

(c)

Figure 5: Schematic of different states of the bridge during the see-saw mechanism: (a) port 1 "ON” and port 2 "OFF," (b) both "OFF," and (c) port 1 "OFF" and port 2 "ON."

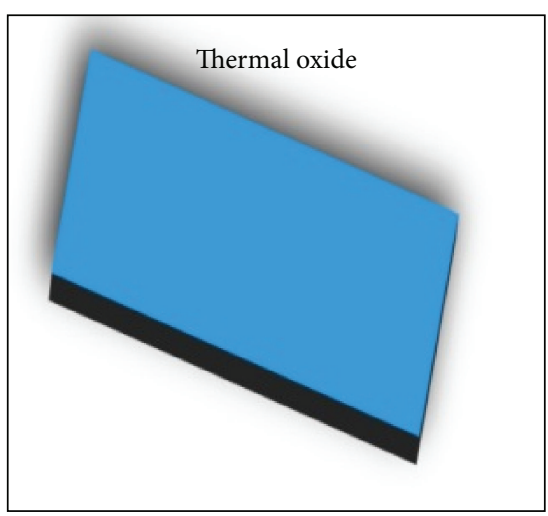

(a)

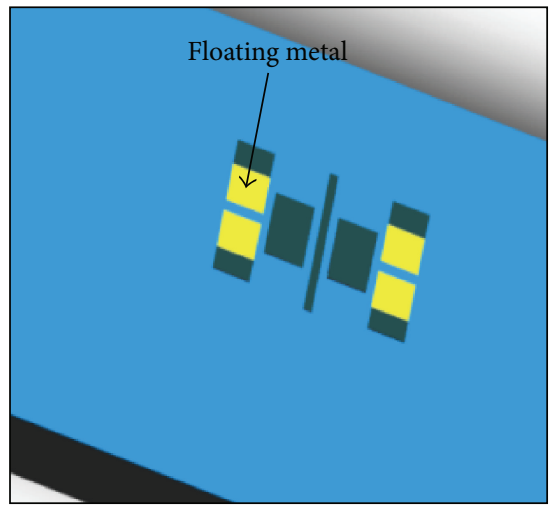

(d)

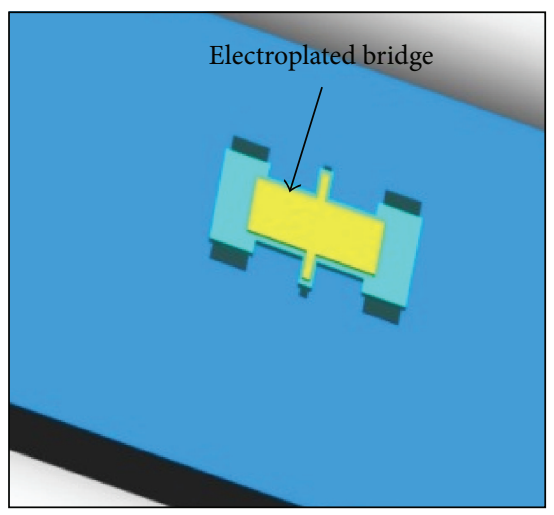

(g)

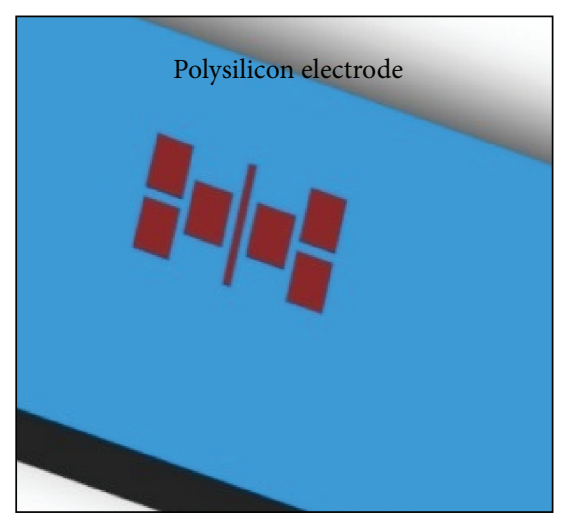

(b)

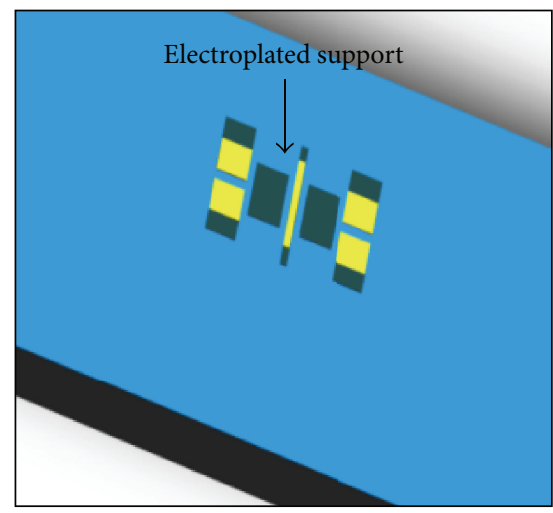

(e)

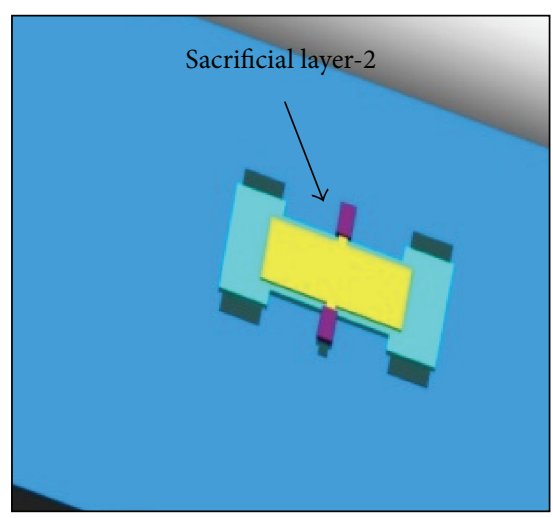

(h)

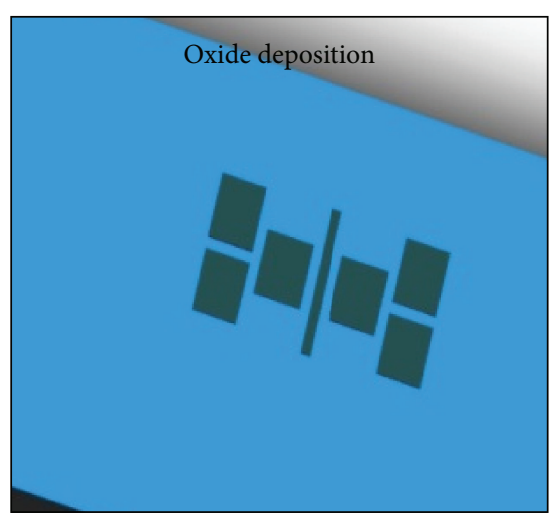

(c)

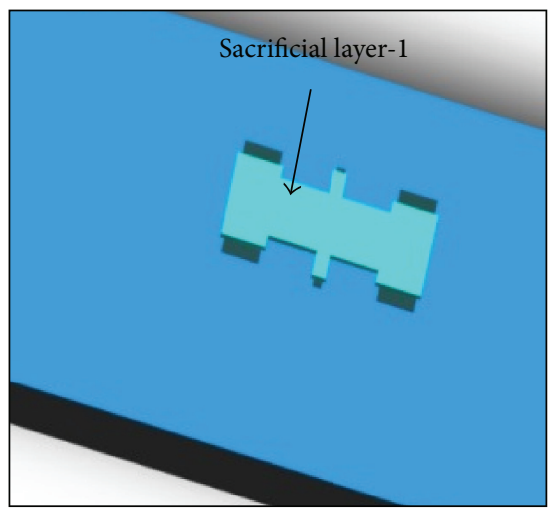

(f)

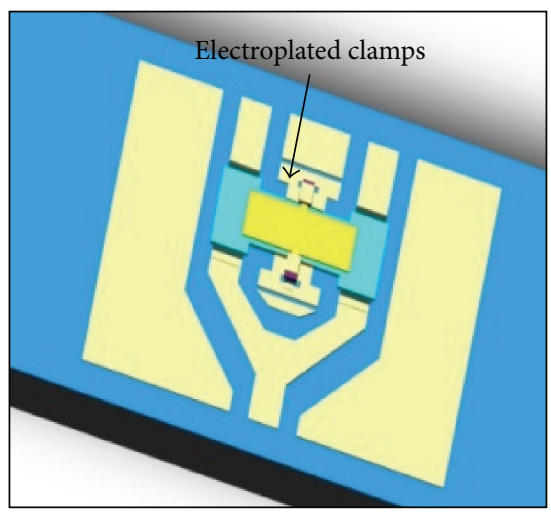

(i)

FIGURE 6: Fabrication process flow for the SPDT switch. 
TABLE 2: Literature survey of size, pull-in voltage, switching time, and number of switches used in the SPDT switch.

\begin{tabular}{|c|c|c|c|c|c|}
\hline \multirow{2}{*}{ SN } & \multirow{2}{*}{ Device parameter } & \multirow{2}{*}{ The proposed see-saw design } & \multicolumn{3}{|c|}{ Literature } \\
\hline & & & Value & Year & Ref \\
\hline \multirow{4}{*}{1} & \multirow{4}{*}{ Size $\left(\mathrm{mm}^{2}\right)$} & \multirow{4}{*}{$1.08 * 0.68$} & $5.2 * 3.0$ & 2009 & [9] \\
\hline & & & $3.8 * 1.1$ & 2009 & [10] \\
\hline & & & $3.5 * 1.5$ & 2011 & {$[11]$} \\
\hline & & & $0.68 * 0.88$ & 2015 & {$[8]$} \\
\hline \multirow{5}{*}{2} & \multirow{5}{*}{ Pull-in voltage (V) } & \multirow{5}{*}{5} & 34 & 2009 & {$[9]$} \\
\hline & & & 85 & 2011 & {$[11]$} \\
\hline & & & 9.5 & 2014 & {$[12]$} \\
\hline & & & 17 & 2014 & [13] \\
\hline & & & 9 & 2015 & {$[8]$} \\
\hline \multirow{4}{*}{3} & \multirow{4}{*}{ Switching speed $(\mu \mathrm{s})$} & \multirow{4}{*}{0.394} & $30-40$ & 2011 & [11] \\
\hline & & & 27.70 & 2014 & [12] \\
\hline & & & 16.64 & 2014 & {$[13]$} \\
\hline & & & 50 & 2015 & {$[8]$} \\
\hline \multirow{5}{*}{4} & \multirow{5}{*}{ Number of switches } & \multirow{5}{*}{1} & 4 & 2009 & {$[10]$} \\
\hline & & & 2 & 2009 & [9] \\
\hline & & & 2 & 2011 & [11] \\
\hline & & & 4 & 2014 & [13] \\
\hline & & & 1 & 2015 & {$[8]$} \\
\hline
\end{tabular}

where $m, b$, and $k$ are mass of bridge, damping coefficient, and the spring constant of the anchor, respectively. For the springfree system $(k=0)$, switching time is calculated by $[16,17]$

$$
T_{p i}=\frac{2 b g_{o}^{3}}{3 \varepsilon_{o} A V_{\mathrm{act}}^{2}}
$$

where $g_{o}$ is initial gap, $A$ is area, and $V_{\text {act }}$ is applied actuation voltage between electrode and bridge. Damping constant for the rectangular plate is given by [18]

$$
b=\frac{3}{2 \pi} \frac{\mu A^{2}}{g_{o}^{3}}
$$

where $\mu$ is the coefficient of viscosity.

From (6) and (7), calculated switching time is $394 \mathrm{nsec}$ at an actuation voltage of $5 \mathrm{~V}$ under vacuum ( 0.76 torr) conditions.

5.3. Power Handling. The proposed design has a low actuation voltage of $1.7 \mathrm{~V}$ which leads to self-actuation of the bridge as explained in $[18,19]$. Self-actuation by RF power and actuation voltage are closely correlated to each other. The electrostatic force due to RF power is given by (8) and (9) [18]. Consider

$$
F_{e}=\frac{1}{2} \frac{\varepsilon_{o} A}{g^{2}} V_{\mathrm{dc}-\mathrm{eq}}^{2},
$$

where

$$
V_{\text {dc-eq }}=\frac{V_{p k}}{\sqrt{2}}=\sqrt{P Z_{0}} .
$$

The proposed SPDT switch with design parameters mentioned in Table 1 will self-actuate at RF power of 500 mWatt. See-saw mechanism with the second electrode as shown in Figure 2 is used to avoid self-actuation. Two electrodes are placed on opposite sides to control self-actuation. By applying sufficient voltage ( $>$ RF voltage), that is, $5 \mathrm{~V}$ for 500 mWatt at opposite electrode, self-actuation is controlled.

5.4. Reliability. The switch reliability is a function of the large number of parameters like stiction, power handling, temperature, stress, the number of switches, contact forces, creep, and so forth which make it difficult to quantify. In the present design, the switch reliability is improved by controlling three parameters out of all reliability parameters: stiction force, power handling, and the number of switches. The proposed switch design has reduced OFF state contact area by 18 times compared to conventional switches as explained in [6-8]. Stiction forces that are directly proportional to contact area $[20,21]$ are reduced by a factor of 18 . Secondly, power handling is further dependent upon many parameters like temperature, cold/hot switching, stress, self-actuation, and so forth. The see-saw configuration with the second electrode has increased power handling from self-actuation perspective only. Thirdly, numbers of SPST switches utilized in the SPDT configuration are reduced to one which has improved reliability by reducing the switch dependency.

\section{Electromagnetic Analysis}

The SPDT switch is designed in High Frequency Structural Simulator (HFSS) for C to Ku band applications. The electromagnetic responses of the RF MEMS see-saw switch are similar to a conventional anchored switch [8]. OFF state 


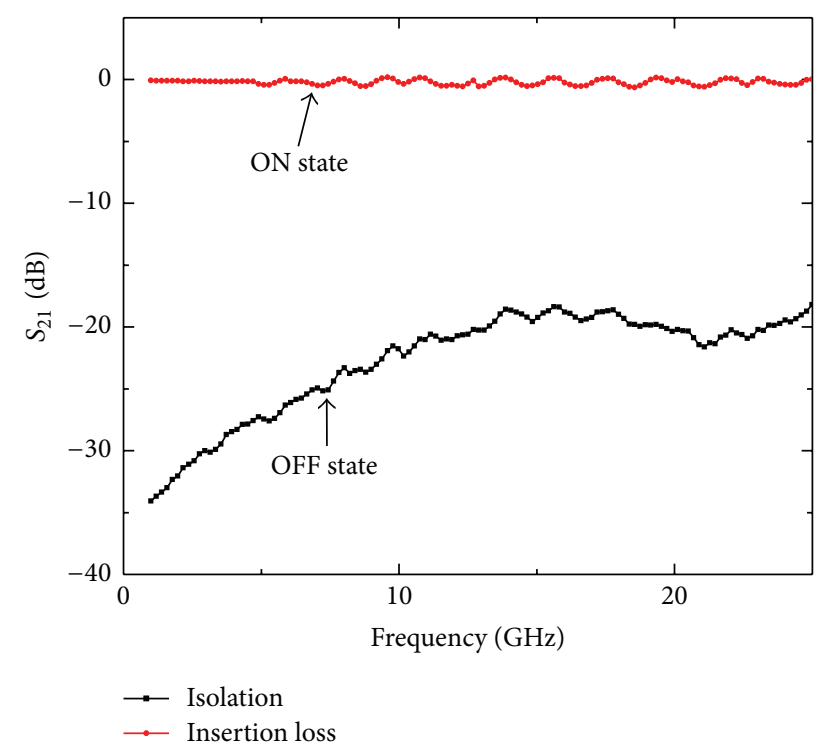

FIGURE 7: Measured S-parameter response of the SPDT switch.

overlap capacitance is reduced to $0.885 \mathrm{fF}$ with floating metal that improves the insertion loss [8] and parasitic capacitance, which also lies in the range of femto-Farad, increases its value to $19 \mathrm{fF}$. In the ON state, overlap capacitance is $2.01 \mathrm{pF}$ and parasitics have a negligible effect on it. Insertion loss lies in the range of $-0.3 \mathrm{~dB}$ to $-0.6 \mathrm{~dB}$ for a wide bandwidth of 19 (120) $\mathrm{GHz}$. Isolation varies from $-28.1 \mathrm{~dB}(@ 1 \mathrm{GHz})$ to $-20 \mathrm{~dB}$ (@20 GHz) as shown in Figure 7.

\section{Conclusions}

The anchor-free see-saw RF MEMS SPDT switch is fabricated using a single series capacitive switch with compact dimensions of $0.734 \mathrm{~mm}^{2}$. The proposed switch has a low actuation voltage of $5 \mathrm{~V}$ with high switching speed (394 nsec). Insertion loss and isolation are better than $-0.6 \mathrm{~dB}$ and $-20 \mathrm{~dB}$, respectively, in the frequency range of $1 \mathrm{GHz}$ to $20 \mathrm{GHz}$.

\section{Competing Interests}

The authors declare that they have no conflict of interests or financial conflicts to disclose.

\section{Acknowledgments}

The authors would like to thank CSIR, India, for providing financial support under Budget Head PSC-0201.

\section{References}

[1] G. Hu, Z. Liu, Y. Qiao et al., "Bonding packaging of a SP4T RF MEMS switch," in Proceedings of the 7th International Conference on Electronics Packaging Technology (ICEPT '06), pp. 1-4, IEEE, Shanghai, China, August 2006.
[2] G. L. Tan, R. E. Mihailovich, J. B. Hacker, J. F. DeNatale, and G. M. Rebeiz, "A very-low-loss 2-bit X-band RF MEMS phase shifters," in Proceedings of the IEEE MTT-S International Microwave Symposium Digest, vol. 1, pp. 333-335, Seattle, Wash, USA, 2002.

[3] M. Daneshmand and R. R. Mansour, "C-type and R-type RF MEMS switches for redundancy switch matrix application," in Proceedings of the IEEE International Microwave Symposium Digest (MTT-S '06), pp. 144-147, 2006.

[4] M. H. Misran, N. A. Shairi, G. H. The, and M. A. Meor Said, "Design and performance analysis of single biasing based SPDT switch for wireless data communications," in Proceedings of the 5th IEEE Asia-Pacific Conference on Applied Electromagnetics (APACE '12), pp. 363-366, Melaka, Malaysia, December 2012.

[5] G. M. Rebeiz and J. B. Muldavin, "RF MEMS switches and switch circuits," IEEE Microwave Magazine, vol. 2, no. 4, pp. 5971, 2001.

[6] D. Bansal, A. Bajpai, P. Kumar, A. Kumar, M. Kaur, and K. Rangra, "Design and fabrication of a reduced stiction radio frequency MEMS switch," Journal of Micro/Nanolithography, MEMS, and MOEMS, vol. 14, no. 3, Article ID 035002, 2015.

[7] L. X. Zhang and Y.-P. Zhao, "Electromechanical model of RF MEMS switches," Microsystem Technologies, vol. 9, no. 6-7, pp. 420-426, 2003.

[8] D. Bansal, A. Kumar, A. Sharma, and K. J. Rangra, "Design of compact and wide bandwidth SPDT with anti-stiction torsional RF MEMS series capacitive switch," Microsystem Technologies Journal, vol. 21, no. 5, pp. 1047-1052, 2015.

[9] Y. Uno, K. Narise, T. Masuda et al., "Development of SPDTstructured RF MEMS switch," in Proceedings of the 15th International Conference on Solid-State Sensors, Actuators and Microsystems (TRANSDUCERS '09), pp. 541-544, June 2009.

[10] S. Cheng, P. Rantakari, R. Malmqvist et al., "Switched beam antenna based on RF MEMS SPDT switch on quartz substrate," IEEE Antennas and Wireless Propagation Letters, vol. 8, pp. 383386, 2009.

[11] D. Yamane, W. Sun, H. Fujita, H. Toshiyoshi, and S. Kawasaki, "Development of a Dual-SPDT RF-MEMS switch for Ku-band," in Proceedings of the IEEE Radio and Wireless Symposium (RWW '10), pp. 432-435, New Orleans, La, USA, January 2010.

[12] U. K. Kommuri, "Design of low voltage RF MEMS switch at 35 GHz," Microwave and Optical Technology Letters, vol. 56, no. 6, pp. 1483-1486, 2014.

[13] U. Sharma, M. Kumar, K. K. Jain, and R. K. Bhan, "Broadband design of RF MEMS SPDT switch," International Journal of Engineering Sciences \& Emerging Technologies, vol. 6, no. 4, pp. 405-409, 2014.

[14] R. Marcelli, G. Bartolucci, G. Minucci, B. Margesin, F. Giacomozzi, and F. Vitulli, "Lumped element modeling of coplanar series RF MEMS switches," Electronics Letters, vol. 40, no. 20, pp. 1272-1274, 2004.

[15] D. Bansal, A. Kumar, A. Sharma, P. Kumar, and K. J. Rangra, "Design of novel compact anti-stiction and low insertion loss RF MEMS switch," Microsystem Technologies, vol. 20, no. 2, pp. 337-340, 2014.

[16] R. K. Gupta and S. D. Senturia, "Pull-in time dynamics as a measure of absolute pressure," in Proceedings of the 10th Annual International Workshop on Micro Electro Mechanical Systems (MEMS '97), pp. 290-294, Nagoya, Japan, January 1997.

[17] S. Dushman and J. Lagerty, Scientific Foundations of Vacuum Technique, John Wiley \& Sons, New York, NY, USA, 1962. 
[18] G. M. Rebeiz, RF MEMS Theory, Design, and Technology, John Wiley \& Sons, Hoboken, NJ, USA, 2003.

[19] R. Malmqvist, R. Jonsson, C. Samuelsson et al., "Self-actuation tests of ohmic contact and capacitive RFMEMS switches for wideband RF power limiter circuits," in Proceedings of the 35th International Semiconductor Conference (CAS '12), pp. 217-220, IEEE, Sinaia, Romania, October 2012.

[20] N. Tas, T. Sonnenberg, H. Jansen, R. Legtenberg, and M. Elwenspoek, "Stiction in surface micromachining," Journal of Micromechanics and Microengineering, vol. 6, no. 4, pp. 385-397, 1996.

[21] Y.-P. Zhao, L. S. Wang, and T. X. Yu, "Mechanics of adhesion in MEMS - a review," Journal of Adhesion Science and Technology, vol. 17, no. 4, pp. 519-546, 2003. 


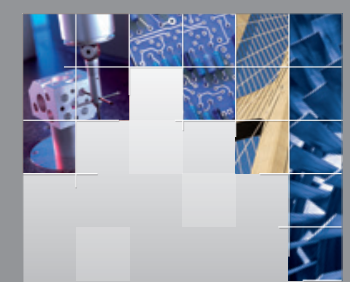

\section{Enfincering}
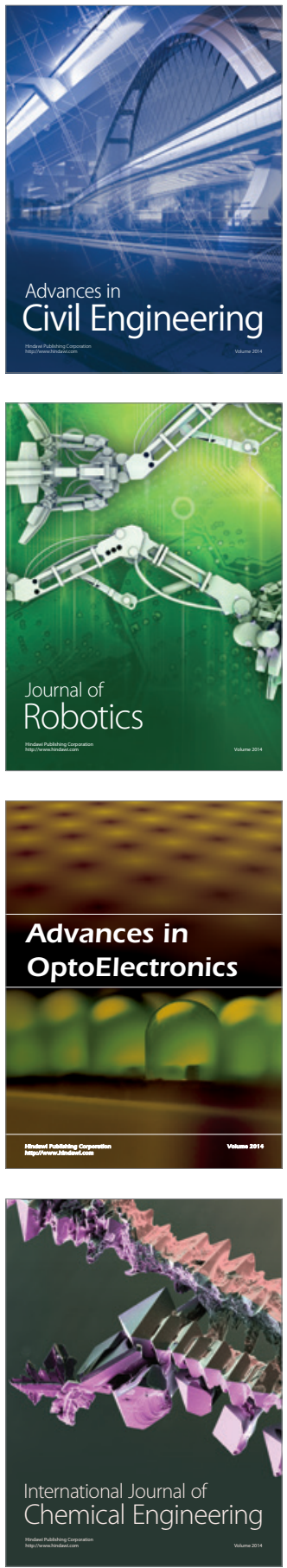

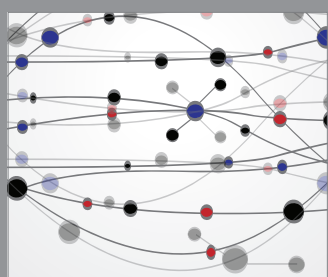

The Scientific World Journal

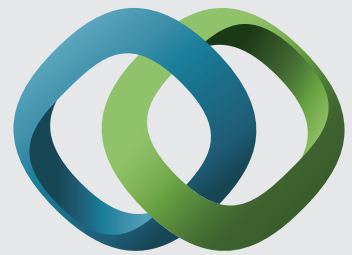

\section{Hindawi}

Submit your manuscripts at

http://www.hindawi.com
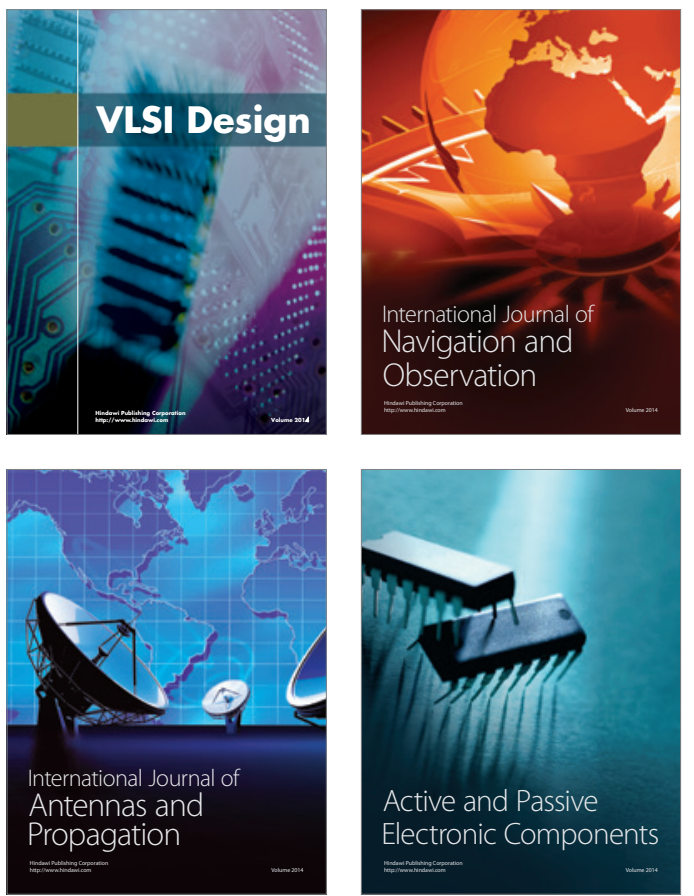
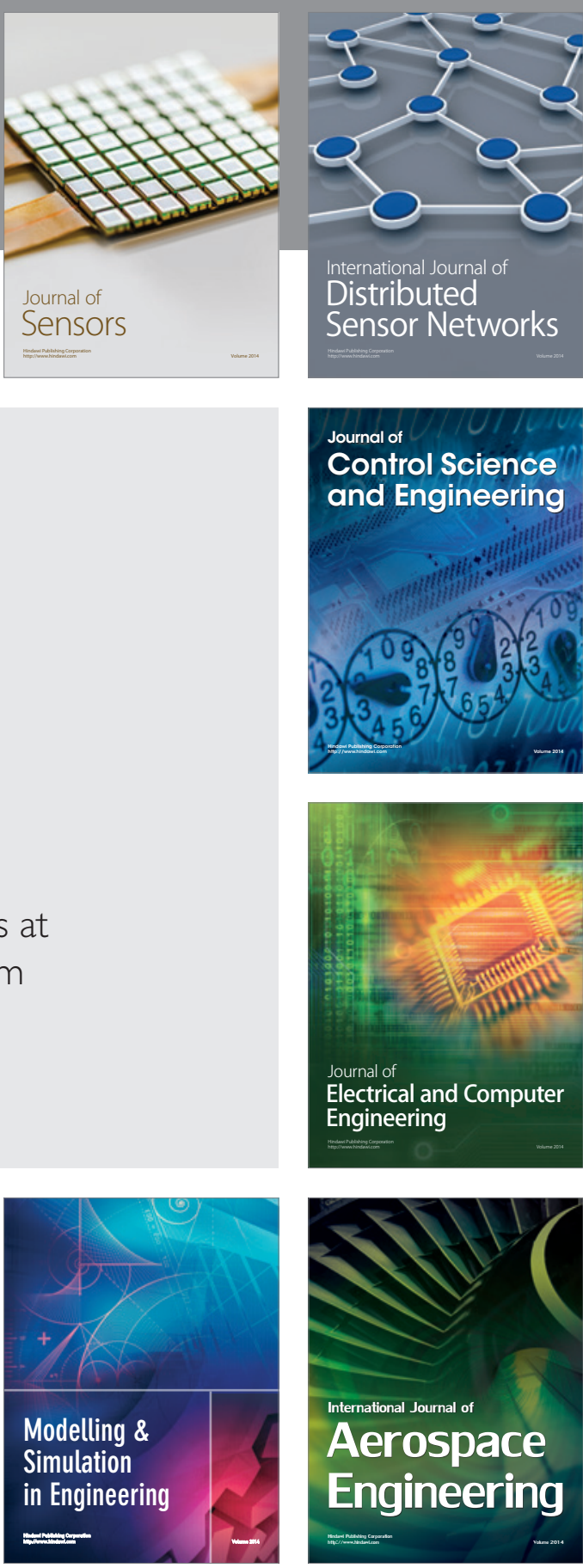

International Journal of

Distributed

Sensor Networks

Journal of

Control Science

and Engineering
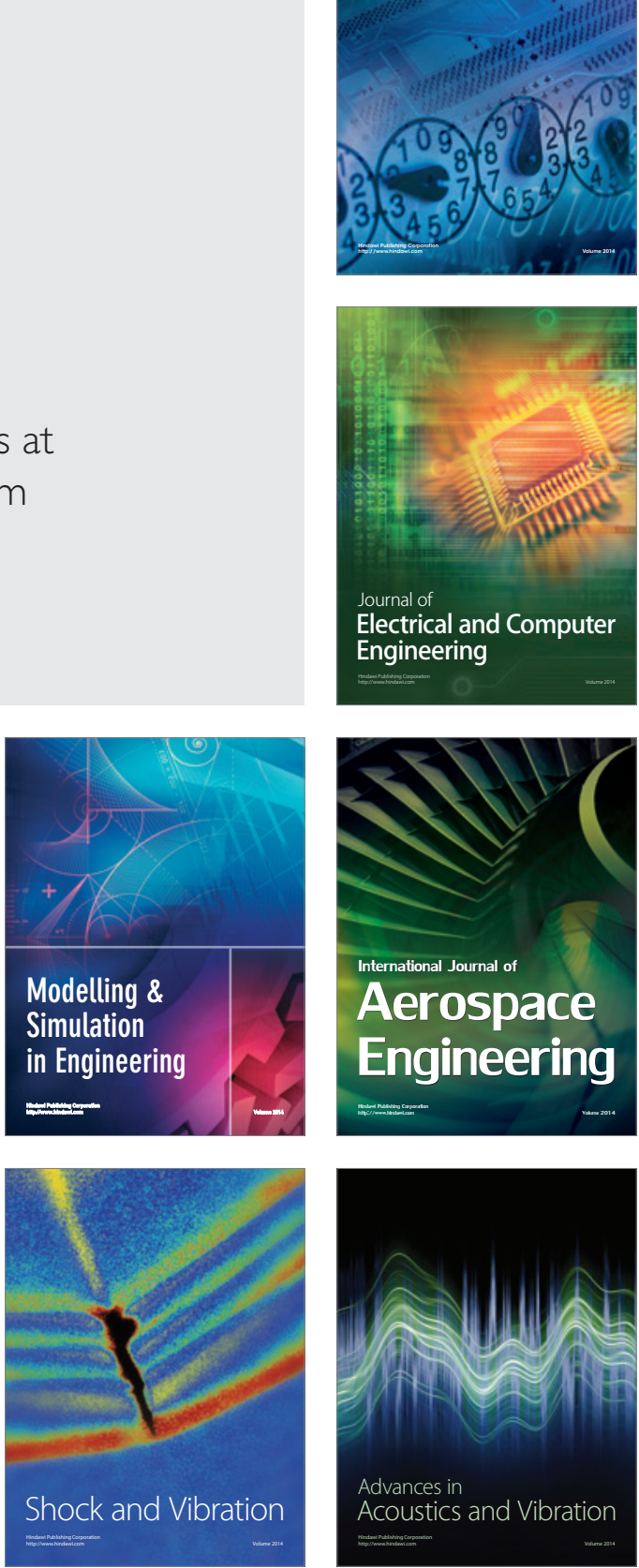